\title{
PENGGUNAAN KARTU "MATCH GAME FOR BILOKS" UNTUK MENINGKATKAN HASIL BELAJAR DAN KEAKTIFAN PESERTA DIDIK KELAS X IPA 2 MAN 10 JAKARTA
}

\author{
Yuliana Dwi Asworo \\ Madrasah Aliyah Negeri 10 Jakarta, Indonesia \\ E-mail: yadaaisyah@gmail.com
}

\begin{abstract}
The difficulty of students remembering and understanding oxidation numbers (Biloks) and compound nomenclature of ionic compounds and kovalen compounds makes the teacher think how to make learning activities more fun and memorable so that learning material can be remembered by students. One way to increase quality of learning is using media. In this study the authors used Match Game for Biloks. This media is applied in the redoks chapter of the oxidation number and compound nomenclature in chemistry class X semester 2 and it can also refresh the memories of class XII first semester students before entering redox material. This innovation was tested in class X IPA2 MAN 10 Jakarta in the 2019/2020 academic year with 36 students consisting of 11 boys and 25 girls. The impact of the innovation to students learning activity and learning goals was observed through questionnaires and test. This game is inspired by domino games, where each player must pair the card he has with the previous card. The making this media by determining the 60 elements/compound/ion molecular formulas along with their names and the oxidation number of the elements to be asked are given different colors in the molecular formula after that make the card "match game". After this media has finished that match games are played in groups and each group has a teacher assistant (expert student) who holds the answer key from the match game it has to correct the answer of their friends. This game uses certain rules by distributing 30 dominoes to the five students so that the winner of the students is the one who runs out first and gets the highest score.
\end{abstract}

Keywords: compound nomenclature; match game; media; oxidation number

\begin{abstract}
Abstrak
Sulitnya siswa mengingat maupun memahami materi tentang bilangan oksidasi (Biloks) dan tata nama senyawa ion maupun senyawa kovalen membuat guru berfikir keras bagaimana caranya membuat kegiatan pembelajaran di kelas berlangsung menyenangkan dan berkesan agar materi pembelajaran diingat siswa. Salah satu cara agar kegiatan pembelajaran di kelas menjadi "hidup" adalah penggunaan media pembelajaran. Artikel ini adalah laporan dari best praciteces dalam bentu berinovasi untuk menunjang kegiatan pembelajaran yang disebut Match Game for Biloks. Media ini diterapkan pada bab redoks materi biloks dan Tata Nama senyawa di pelajaran kimia kelas X semester 2 serta bisa juga untuk merefresh ingatan siswa kelas XII semester 1 sebelum masuk materi Redoks. Inovasi ini telah diuji coba di kelas X IPA2 MAN 10 Jakarta Barat pada tahun pelajaran 2019/2020 dengan jumlah siswa sebanyak 36 peserta didik yang terdiri dari 11 laki-laki dan 25 perempuan. Dampak dari inovasi terhadap kegiatan dan hasil belajar diamati dan diukur menggunakan angket dan soal. Media dibuat dengan cara menentukan 60 rumus molekul unsur/senyawa/ion beserta namanya dan biloks unsur yang akan ditanyakan diberikan warna beda dalam rumus molekulnya, setelah itu membuat kartu "match game". Berdasarkan uji coba, media ini telah berdampak terhadap peningkatan mutu proses dan hasil belajar.
\end{abstract}

Kata Kunci: Biloks, match game, media, tata nama senyawa 


\section{PENDAHULUAN}

Kurikulum 2013 bertujuan untuk mempersiapkan manusia Indonesia agar memiliki kemampuan hidup sebagai pribadi dan warga negara yang beriman, produktif, kreatif, inovatif, dan afektif serta mampu berkontribusi pada kehidupan bermasyarakat, berbangsa, bernegara, dan peradaban dunia. Hal tersebut sejalan dengan pembelajaran kimia yang menekankan kepada praktek agar peserta didik dapat berkarya dan bersikap kreatif untuk lebih memahami materi pembelajaran.

Materi tentang bilangan oksidasi adalah salah satu dasar peserta didik untuk bisa menguasai materi tentang Reaksi Reduksi Oksidasi dilihat dari konsep kenaikan biloks (oksidasi) maupun penurunan biloks (reduksi). Biloks atau tingkat oksidasi unsur merupakan nilai muatan atom dalam suatu molekul atau ion. Biloks terdapat dalam unsur bebas, molekul senyawa, maupun molekul ion.

Mengenai materi tata nama senyawa, banyak juga peserta didik yang belum paham dan sulit mengerjakan soal yang berhubungan dengan tata nama senyawa, karena materi tata nama senyawa mempunyai tingkat kesulitan yang cukup tinggi. Ia memiliki banyak aturan yang harus diperhatikan saat memberikan nama atau membuat rumus kimia suatu senyawa. Tata nama senyawa merupakan salah satu materi kimia yang dipelajari di kelas X SMA pada dasarnya dipersiapkan sebagai bekal pelajaran kimia selanjutnya, sehingga keberhasilannya sangat ditekankan.

Materi Redoks dan tata nama senyawa juga merupakan materi yang selalu dikeluarkan dalam Ujian Nasional. Ujian Nasional Tahun lalu terdapat 3 soal yang berhubungan dengan Redoks dan tata nama senyawa, yaitu di nomor 23-25. Sedangkan materi ikatan kimia terdapat pada soal nomor 1 di soal UN tahun 2017-2018. Apabila peserta didik belum paham akan sulit mengerjakan soal yang berhubungan dengan materi tersebut, maka penguasaan konsep peserta didik itu masih rendah sehingga akan berpengaruh pada pencapaian hasil belajar yang belum maksimal, sehingga diperlukanlah inovasi pembelajaran kimia agar konsep materi mudah difahami siswa.

Sulitnya peserta didik mengingat maupun memahami materi tentang ikatan kimia, bilangan oksidasi (biloks), tata nama senyawa ion maupun senyawa kovalen membuat guru berfikir keras bagaimana caranya membuat kegiatan pembelajaran di kelas berlangsung dengan menyenangkan dan berkesan agar materi pembelajaran diingat peserta didik.

Melalui bermain, peserta didik dapat mengembangkan potensi kecerdasan, keterampilan motorik, kemampuan sosial, emosi dan kepribadian. Sukmadinata (Wardany, 2016) menyatakan bahwa melalui 
bermain, peserta didik belajar mengembangkan pengetahuannya mengenai sesuatu hal (learning to know), peserta didik belajar untuk dapat melakukan sesuatu sesuai dengan konteksnya (learning to do), peserta didik juga dapat belajar untuk dirinya sekaligus empati terhadap orang lain (learning to live together).

Oleh karena itu, penulis melakukan inovasi membuat media "Match Game" untuk materi Redoks dan tata nama senyawa sehingga tercipta pembelajaran yang aktif dan menyenangkan, serta peserta didik dapat belajar bersama dalam kelompoknya dan melatih jiwa berkompetisi sehat. Dalam permainan ini juga, guru memberikan kesempatan kepada peserta didik untuk menjadi tutor sebaya sehingga dapat membantu guru dan menguatkan pemahamannya terhadap materi yang dipelajari.

Untuk mempelajari penerapan permainan terebut dilakukan sebuah penelitian tindakan sebuah penelitian Tindakan dengan rumusan masalah Apakah media pembelajaran "Match Game for Biloks" dapat membuat peserta didik menjadi lebih aktif dalam pembelajaran kimia? Bagaimana hasil belajar kimia peserta didik kelas $\mathrm{X}$ MIPA1 dengan menggunakan media "Match Game for Biloks" pada materi Redoks?

Sedangkan tujuan penelitian ini adalah Untuk mengetahui apakah media pembelajaran "Match Game for Biloks" ini dapat membuat peserta didik menjadi lebih aktif dalam pembelajaran kimia. Dan untuk mengetahui bagaimana hasil belajar kimia peserta didik kelas X MIPA1 dengan menggunakan media "Match Game for Biloks" pada materi Redoks.

Manfaat penelitian ini ditunjukkan kepada 3 pihak, yaitu:

1. Manfaat Bagi Peserta Didik:

a. Melatih peserta didik agar lebih aktif belajar, antusias, dan mampu bekerja sama dalam tim/kelompok yang dilandasi atas dasar kejujuran, saling membantu, pantang menyerah dan ulet dalam mencari jawaban dan menjawab soal.

b. Seluruh peserta didik kelas $X$ dan XII MIPA maupun seluruh peserta didik kelas $\mathrm{X}$ lainnya yang memilih lintas minat kimia agar menikmati pelajaran kimia dan lebih diingat.

c. Seluruh peserta didik SMP yang mempelajari Sains dalam penamaan senyawa agar suka terhadap pelajaran kimia (Sains) dan dapat bereksplorasi.

2. Manfaat bagi Guru

Agar dapat mengembangkan metode pembelajaran yang sesuai materi yang dipelajari, lebih kreatif, dan membuat media ajar yang bermanfaat bagi peserta didik serta untuk guru serta menambah angka kredit sebagai inovasi pembelajaran (best practice). sebagai salah satu penilaian kenaikan pangkat.

3. Manfaat bagi Sekolah /Madrasah 
Dapat memberikan sumbangan untuk perbaikan dan peningkatan mutu Sekolah serta hasil Inovasi ini sebagai referensi bagi guru lainnya untuk penelitian selanjutnya.

\section{METODE}

Artikle ini merupakan laporan best practice dari kegiatan inovasi yang penulis lakukan untuk memecahkan permasalahan yang ada di kelas XI IPA2 pada materi mengenai bilangan oksidasi. Penulis menggunakan media match game dalam pembelajaran, dengan tujuan untuk menstimulus peserta didik agar melakukan proses belajar aktif sehingga timbul suasana pembelajaran yang menyenangkan yaitu siswa laki-laki maupun perempuannya tidak mengantuk dan semuanya terlibat aktif dalam kelompoknya masing-masing.

Inovasi ini telah diuji coba di kelas X IPA2 MAN 10 Jakarta Barat pada tahun pelajaran 2019/2020 dengan jumlah siswa sebanyak 36 peserta didik yang terdiri dari 11 laki-laki dan 25 perempuan. Uji coba dilaksanaan tanggal 9 Maret 2020. Dalm uji coba tersebut diamati dampak penggunaan inovasi terhadap aktifitas peserta didik dan diukur hasil belajarnya. Mengukuran dampai terhadap akitifitas dilakukan melalui pengamatan menggunakan menggunakan catatan lapangan dan pengukuran hasil belajar dilakukan melalui penilaian harian menggunakan soal.

\section{HASIL DAN PEMBAHASAN}

\section{Kartu Mach Game}

Kartu Match Game ini menggunakan 2 tipe soal yang memiliki tingkat kesulitan yang hampir sama. Tipe soal pertama digunakan untuk babak penyisihan sedangkan tipe soal kedua untuk babak final.
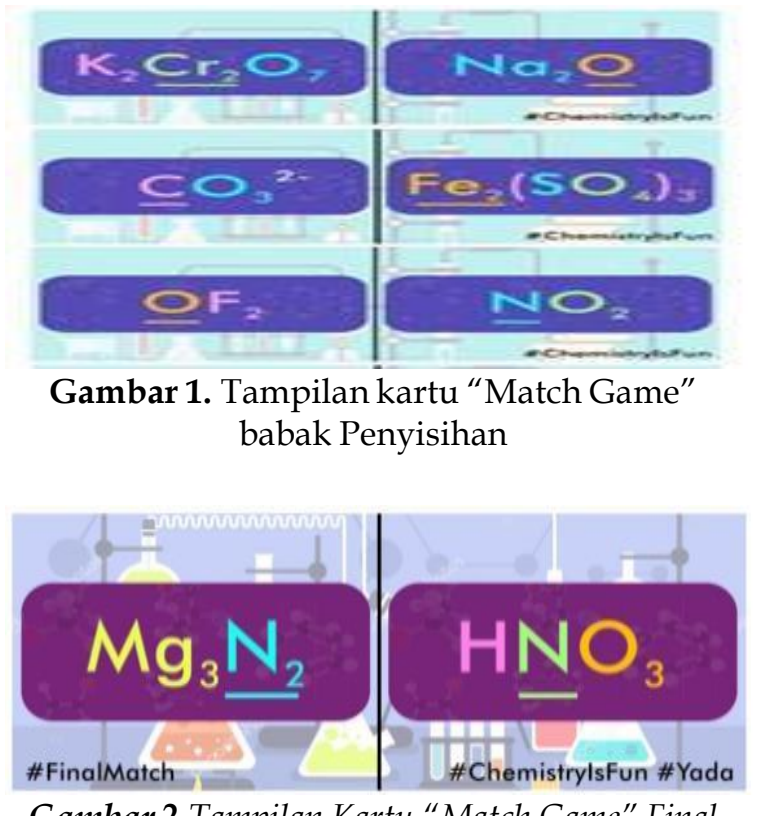

Gambar 2 Tampilan Kartu "Match Game" Final

Setelah media ini selesai, dilakukan match games dalam kelompok. Penerapan metode ini dimulai dengan teknik perwakilan kelompok yang bertugas sebagai asisten guru (peserta didik ahli) diberikan petunjuk cara bermain oleh guru dengan diberikan panduan permaian dan kunci jawaban Biloks dari kartu "Match Game" setelah itu mereka harus mensosialisasikan cara bermain tersebut kepada teman-teman dalam kelompoknya, sehingga mempunyai tanggung jawab dan cukup membekas pada ingatan anak karena metode ini mementingkan daya fikir anak lebih 
Wawasan

Jurnal Balai Diklat Keagamaan Jakarta PISSN 2548-9232; EISSN ...

Volume 1 Nomor 1 Tahun 2020

tinggi untuk dapat mengingat pelajaran yang diberikan oleh guru. Games ini menggunakan aturan tertentu dengan membagikan 30 domino ke 5 peserta didik, sehingga pemenang peserta didik adalah yang mendapatkan skor tertinggi.

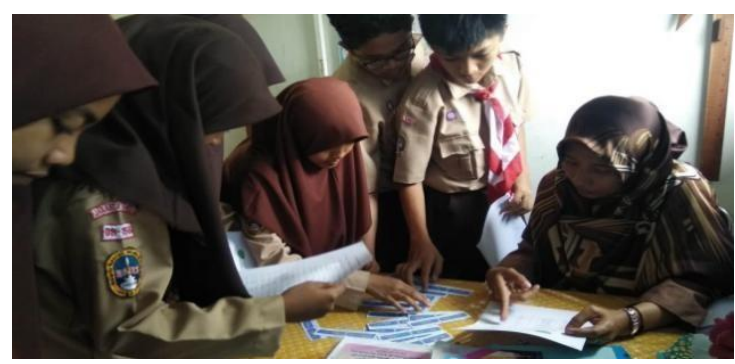

Gambar 3. Guru sedang menjelaskan aturan main dan skoring kepada tim Ahli dari masingmasing kelompok.

Penerapan metode ini dimulai dari teknik yaitu peserta didik ditugaskan mencari biloks masing-masing unsur dari kartu yang didapatnya dan memasangkan dengan kartu lain yang memiliki biloks yang sama sebelum batas waktu berakhir dan peserta didik yang dapat mencocokkan kartunya diberi poin.

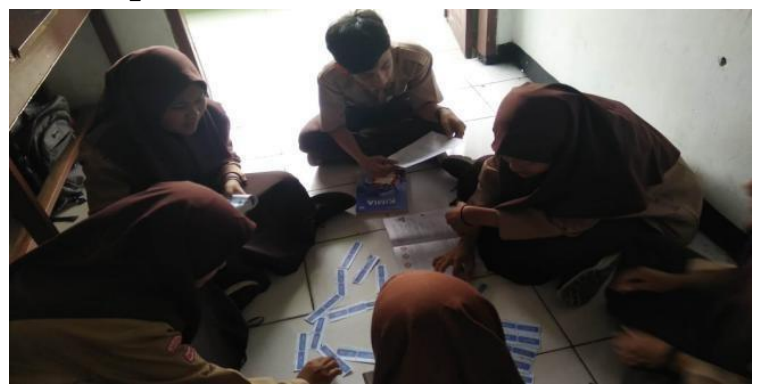

Gambar 4. Peserta didik sedang memasangkan kartunya

Pembelajaran dengan media match game ini merupakan bagian dari pembelajaran kooperatif. Match game melatih peserta didik untuk memiliki sikap sosial yang baik dan melatih kemampuan peserta didik dalam bekerja sama disamping melatih kecepatan berfikir peserta didik. Selain itu, pembelajaran dengan media Match Game membutuhkan ketelitian, kecermatan, ketepatan, dan kecepatan peserta didik dalam memasangkan/mencocokkan kartu yang dipegang sambil belajar mengenai suatu konsep dalam suasana yang menyenangkan.

Perbedaan dengan media sejenis yang sudah ada adalah pada umumnya kartu domino dimainkan dengan cara memasangkan kartu yang satu dengan yang lainnya, sedangkan kartu domino yang penulis buat dimainkan dengan cara memasangkan setiap kartu dengan kartu yang lainnya dengan biloks yang sama atau bisa juga dikembangkan untuk jenis ikatan yang sama atau unsur penyusun senyawa yang sama sehingga terbentuk banyak peluang untuk menjawab.

\section{Data Hasil Uji Caba dan}

\section{Pembahasan}

Peneliti memberikan angket penggunaan media "Match Game" kepada kakak kelas yang sebelumnya menggunakan media ini, tapi dalam bentuk yang belum dimodifikasi, yaitu berupa kertas HVS yang ditulis dengan spidol dalam pembelajaran.

Dari hasil Angket evaluasi penggunaan media "Match Game" yang diberikan kepada seluruh peserta didik kelas XII MIPA1 berjumlah 36 peserta didik dan XI MIPA2 berjumlah 33 peseta didik melalui google form dengan alamat link : https://forms.gle/qfV32fgLfoMofC3y7 
Wawasan

Jurnal Balai Diklat Keagamaan Jakarta PISSN 2548-9232; EISSN ...

Volume 1 Nomor 1 Tahun 2020

diperoleh hasil 56 tanggapan, berarti sampel berjumlah $81,16 \%$, diperoleh hasil sebagai berikut :
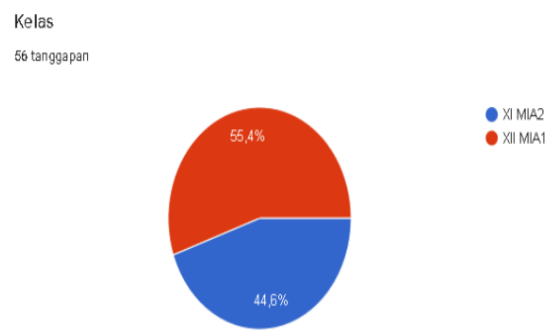

Gambar 5. Grafik pembagian Kelas sebagai Responden

Gambar grafik tersebut, dituangkan dalam tabel sebagai berikut.

Tabel 1. Jumlah sampel penelitian

\begin{tabular}{|c|c|c|}
\hline Kelas & $\%$ angket & $\begin{array}{c}\text { Jumlah } \\
\text { Peserta didik }\end{array}$ \\
\hline XII MIPA1 & $55,4 \%$ & 31 \\
\hline XI MIPA2 & $44,6 \%$ & 25 \\
\hline
\end{tabular}

Selanjutnya data hasil survey direkap dan disajikan dalam data berikut.

Bagaimana penggunaan media "Match Game" dalam pembelajaran Biloks? 56 tanggapan

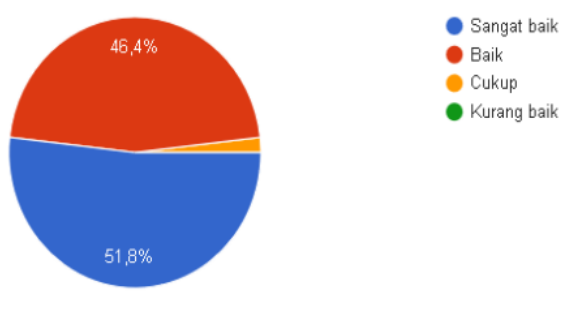

Gambar 5. Hasil angket Soal no.1

Gambar grafik tersebut, dituangkan dalam tabel sebagai berikut:
Tabel 2. Penggunaan media "Match Game" dalam pembelajaran Biloks

\begin{tabular}{|l|c|c|}
\hline Penilaian & $\begin{array}{c}\text { \% } \\
\text { Angket }\end{array}$ & $\begin{array}{c}\text { Jumlah } \\
\text { peserta didik }\end{array}$ \\
\hline sangat baik & $51,8 \%$ & 29 \\
\hline Baik & $46,4 \%$ & 26 \\
\hline Cukup & $1,8 \%$ & 1 \\
\hline kurang baik & - & - \\
\hline
\end{tabular}

Dari angket no. 1, dapat disimpulkan media ini baik digunakan dalam pembelajaran Biloks. Karena dominan yang menjawab adalah 29 dari 56 responden, yaitu sebanyak 51,8\% dan yang menjawab baik juga banyak, yaitu 26 dari 56 responden atau sebanyak 46,4\%. Berarti media ini sangat bisa digunakan dalam pembelajaran biloks.

Dari angket no. 2, dapat disimpulkan media ini baik digunakan dalam pembelajaran Tata nama senyawa yang berhubungan dengan materi redoks, karena 31 dari 56 responden yang menjawab sangat baik, yaitu sebanyak 55,4\%, setelah itu yang menjawab baik juga banyak, yaitu 22 dari 56 responden atau sebanyak 39,3\%.

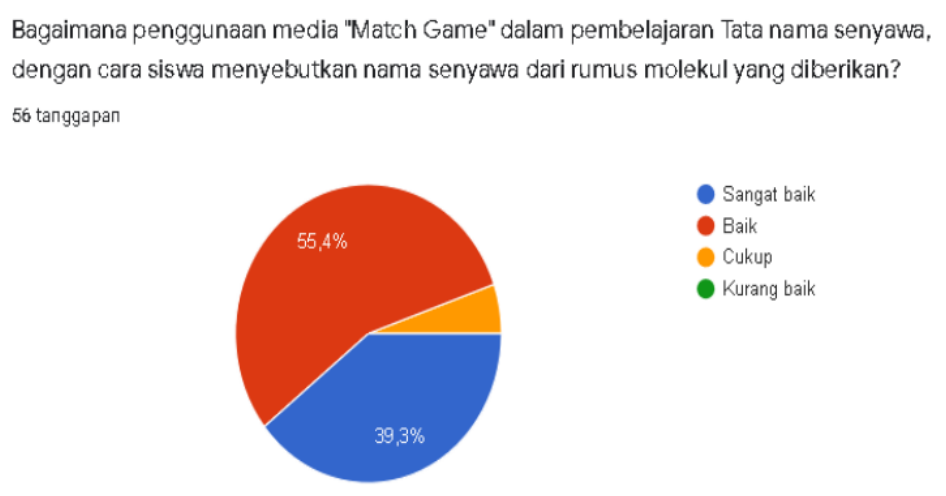

Gambar 6. Hasil Angket Pernyataan 2 
Gambar grafik tersebut, dituangkan dalam tabel sebagai berikut:

Tabel 4. Tanggapan responden untuk mengetahui apakah media "Match Game" dapat membantu peserta didik dalam mempelajari Biloks

\begin{tabular}{|c|c|c|}
\hline Penilaian & \% Angket & $\begin{array}{c}\text { Jumlah } \\
\text { peserta didik }\end{array}$ \\
\hline Iya & $98,2 \%$ & 55 \\
\hline Tidak & $1,8 \%$ & 1 \\
\hline
\end{tabular}

Dari soal angket no. 3 Dapat disimpulkan media ini sangat membantu peserta didik dapat mempelajari biloks karena dijawab dominan oleh responden yaitu sebanyak 55 dari 56 responden atau sebanyak $98,2 \%$, dan hanya 1 peserta didik $(1,8 \%)$ yang menjawab tidak dari 56 responden. Berarti media ini sangat membantu peserta didik untuk mempelajari biloks dengan mudah dan menyenangkan.

Bagaimana tampilan "Match Game" yang terdapat dalam gambar? 56 tanggapan

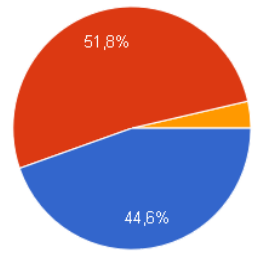

Gambar 8. Hasil angket Soal 3

Gambar grafik tersebut, dituangkan dalam tabel sebagai berikut:

Tabel 5. Tampilan "Match Game" yang terdapat dalam gambar.

\begin{tabular}{|c|c|c|}
\hline Penilaian & $\%$ Angket & $\begin{array}{c}\text { Jumlah } \\
\text { peserta didik }\end{array}$ \\
\hline
\end{tabular}

\begin{tabular}{|c|c|c|}
\hline $\begin{array}{c}\text { Sangat } \\
\text { menarik }\end{array}$ & $44,6 \%$ & 25 \\
\hline Menarik & $51,8 \%$ & 29 \\
\hline Cukup & $3,6 \%$ & 2 \\
\hline Kurang & - & - \\
\hline
\end{tabular}

Dari angket no. 4 tentang tampilan media "Match Game" yang digunakan dslam pembelajaran, yang menjawab sangat menarik sebanyak 25 dari 56 responden atau sebanyak 44,6\% dan yang menjawab menarik dominan dijawab oleh responden, sebanyak 29 dari 56 responden atau sebanyak 51,8\%. Sehingga dapat disimpulkan media ini menarik untuk dilihat, maupun digunakan sebagai media pembelajaran karena tampilannya yang menarik dan berwarna.

Dari hasil Penilaian harian $\begin{array}{llll}\text { peserta didik pada KD } 3.9 & \end{array}$ Mengidentifikasi reaksi reduksi dan oksdasi menggunakan konsep bilangan oksidasi diperoleh hasil rata-rata $\mathrm{PH}$ yang meningkat yaitu 74,97, dengan jumlah peserta didik yang mendapat nilai di bawah KKM sebanyak 12 siswa dibandingkan $\mathrm{PH}$ tahun sebelumnya di KD yang sama, yang memiliki rata-rata PH 65,1 dengan jumlah peserta didik yang mendapat nilai di bawah KKM sebanyak 15 siswa. Hal tersebut membuktikan bahwa Media "Match Game" for biloks dapat meningkatkan pemahaman konsep sehingga penilaian hariannya ikut meningkat. 
Tabel 6. Perbandingan hasil Penilaian Harian KD3.9

\begin{tabular}{|c|c|c|c|}
\hline Kelas & $\begin{array}{c}\text { Nilai } \\
\text { Rata- } \\
\text { rata } \\
\text { PH } \\
\text { KD } \\
\mathbf{3 . 9}\end{array}$ & $\begin{array}{c}\text { Jumlah } \\
\text { peserta } \\
\text { didik } \\
\text { yang } \\
\text { mendapat } \\
\text { nilai } \\
\text { dibawah } \\
\text { KKM }\end{array}$ & $\begin{array}{c}\text { Jumlah } \\
\text { peserta } \\
\text { didik yang } \\
\text { mendapat } \\
\text { nilai } \\
\text { diatas } \\
\text { KKM }\end{array}$ \\
$\begin{array}{c}\text { X MIPA2 } \\
\text { TP } \\
2018 / 2019\end{array}$ & 65,1 & 15 siswa & 18 siswa \\
\hline $\begin{array}{c}\text { X MIPA2 } \\
\text { TP } \\
2019 / 2020\end{array}$ & 74,97 & 12 siswa & 24 siswa \\
\hline
\end{tabular}

Hasil Pembelajaran di kelas dengan Pembelajaran kooperatif Menggunakan Media Match game yaitu:

1. Suasana kompetitif dan kegembiraan akan tumbuh dalam proses pembelajaran, karena peserta didik belajar menyelesaikan tantangan serta berusaha mendapatkan skor tertinggi dengan menjawab yang benar.

2. Munculnya dinamika sifat kompetitif antarseluruh peserta didik, sehingga keaktifan peserta didik dalam pembelajaran terlihat.

3. Peserta didik mencari pasangan biloks yang sama dengan belajar tentang suatu konsep biloks dalam suasana menyenangkan.
4. Peserta
didik
belajar
menghitung/mencari
jawaban
dengan cepat sehingga dapat memanfaatkan waktunya dengan baik.

5. Kegiatan pembelajaran ini dapat dilakukan dimana saja, tergantung kesepakatan peserta didik, bisa berkeliling mengitari meja atau di lantai, sehingga mereka nyaman dalam belajar dan belajar memutuskan suatu hal secara Bersama.

6. Meningkatnya hasil Penilaian Harian peserta didik dan tumbuhnya rasa percaya diri untuk berkompetisi serta bersaing dengan temannya.

Berdasarkan pembahasan diatas,membuktikan bahwa Media "Match Game for Biloks" ini memberikan hasil yang sangat bagus, baik dari segi peningkatan keaktifan peserta didik maupun meningkatkan hasil penilaian harian yang meningkat dari tahun sebelumnya pada materi yang sama.

\section{KESIMPULAN}

Kesimpulan dari penelitian ini adalah sebagai berikut:

1. Media "Match Game for Biloks" ini terbukti membuat hasil penilaian harian pada materi Redoks meningkat sehingga media ini terbukti dapat digunakan dalam kegiatan pembelajaran.

2. Media "Match Game for Biloks" ini juga terbukti membuat peserta didik aktif dalam mengikuti pembelajaran karena setiap peserta didik turut serta dalam melaksanakan tugas belajarnya, terlibat dalam kegiatan pembelajaran "Match game", bertanya kepada siswa lain atau guru jika mengalami kesulitan dan berusaha mencari informasi untuk 
memecahkan masalahnya yaitu mencari nilai biloks dalam kartu yang dipegangnya.

Saran peneliti untuk penelitian selanjutnya yang bisa dilakukan setelah diilakukan penelitian ini adalah:

1. Match game bisa digunakan guru untuk kuis maupun Penilaian harian lisan. karena dapat mengajak peserta didik untuk berfikir cepat dalam waktu yang ditentukan.

2. Guru dapat mengembangkan lagi rumus molekul atau struktur untuk pembelajaran pada materi yang lain.

3. Guru dapat mengembangkan lagi rumus molekul untuk dicari bentuk molekulnya agar kartu Match game menjadi multi guna.

\section{DAFTARPUSTAKA}

Fernando, Haru. (2007). Penggunaan Algoritma Brute Force dan Greedy dalam Permainan Domino. Jurnal Institut Teknologi Bandung.

Herfiana, Mita. (2016). Penguasaan Konsep Pada Materi Tata Nama Senyawa Melalui Pembelajaran Berbasis Inkuiri Peserta didik Kelas X SMAN I. Skripsi. Fakultas Tarbiyah Dan Keguruan Universitas Islam Negeri Ar-rainy DarussalamBanda Aceh. Diakses pada 26 September 2019.

Putadi, Sukisman (2006). Kartu Domino Ion dalam Pembelajaran Rumus Molekul Ionik di Kelas X. Prosiding Seminar Nasional Kimia dan Pendidikan Kimia. FMIPA UNY.

Risman (2012). Model-model Pembelajaran Mengembangkan Profesionalisme. Jakarta: Rajawali Press.

Sudarmo, U. (2016). Bilangan Oksidasi. In L. E. Redoks, KIMIA UNTUK SMA/MA KELAS X (hal. 149 - 150). Surakarta: Erlangga.

Suterna, N. d. (2016). Aktif dan Kreatif Belajar Kimia Kelas X Peminatan (hal. 110). Bandung: Grafindo Mediapratama.

Unknown. (2015), March 17. idtesis.com. diunduh dari https://idtesis.com/metodepembelajaran-make-match/.

Utami, Budi. Nugroho, Agus C. Mahardiani Lina. Yamtinah, Sri dan Mulyani, Bakti. (2009). KIMIA 1: Untuk SMA/MA kelas X. Jakarta. Departemen Pendidikan Nasional. 